\title{
Remarkable dynamics of nanoparticles in the urban atmosphere
}

\author{
M. Dall'Osto ${ }^{1, *}$, A. Thorpe ${ }^{1}$, D. C. S. Beddows ${ }^{1}$, R. M. Harrison ${ }^{1}$, J. F. Barlow ${ }^{2}$, T. Dunbar ${ }^{2}$, P. I. Williams ${ }^{3}$, and \\ H. $\mathrm{Coe}^{3}$ \\ ${ }^{1}$ National Centre for Atmospheric Science, Division of Environmental Health and Risk Management, School of Geography, \\ Earth \& Environmental Sciences, University of Birmingham, Edgbaston, Birmingham, UK \\ ${ }^{2}$ Department of Meteorology, University of Reading, Earley Gate, P.O. Box 243, Reading Berkshire, RG6, 6BB, UK \\ ${ }^{3}$ National Centre for Atmospheric Science, School of Earth, Atmospheric \& Environmental Sciences, University of \\ Manchester, Williamson Building, Oxford Road Manchester M13 9PL, UK \\ *present address: Institute of Earth Sciences "Jaume Almera", Consejo Superior de Investigaciones Científicas (CSIC) \\ C/LLuis Solé i Sabarís s/n, 08028 Barcelona, Spain
}

Received: 7 October 2010 - Published in Atmos. Chem. Phys. Discuss.: 16 December 2010

Revised: 5 May 2011 - Accepted: 19 June 2011 - Published: 12 July 2011

\begin{abstract}
Nanoparticles emitted from road traffic are the largest source of respiratory exposure for the general public living in urban areas. It has been suggested that adverse health effects of airborne particles may scale with airborne particle number, which if correct, focuses attention on the nanoparticle (less than $100 \mathrm{~nm}$ ) size range which dominates the number count in urban areas. Urban measurements of particle size distributions have tended to show a broadly similar pattern dominated by a mode centred on 20-30 nm diameter emitted by diesel engine exhaust. In this paper we report the results of measurements of particle number concentration and size distribution made in a major London park as well as on the BT Tower, $160 \mathrm{~m}$ aloft. These measurements taken during the REPARTEE project (Regents Park and BT Tower experiment) show a remarkable shift in particle size distributions with major losses of the smallest particle class as particles are advected away from the traffic source. In the Park, the traffic related mode at $20-30 \mathrm{~nm}$ diameter is much reduced with a new mode at $<10 \mathrm{~nm}$. Size distribution measurements also revealed higher number concentrations of sub-50 nm particles at the BT Tower during days affected by higher turbulence as determined by Doppler Lidar measurements and are indicative of loss of nanoparticles from air aged during less turbulent conditions. These results are suggestive of nanoparticle loss by evaporation, rather than coagulation processes. The results have major implications for understanding the impacts of traffic-generated particulate matter on human health.
\end{abstract}

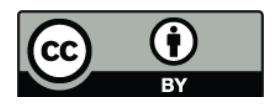

Correspondence to: R. M. Harrison (r.m.harrison@bham.ac.uk)

\section{Introduction}

Urban air pollution is one of the environmental problems of major concern and will, due to growing urbanization, probably become increasingly important in the future. Particulate matter is one of the key urban pollutants and much attention has focussed on the smaller size fractions. Ultrafine particles (UF) are defined as those with diameters smaller than $0.1 \mu \mathrm{m}(100 \mathrm{~nm})$, and nanoparticles as particles with one dimension smaller than $100 \mathrm{~nm}$. The size of airborne particles is heavily influenced by the multiplicity of sources and processes which lead to their emission and formation, and therefore, by the material from which the particles were formed. The interest in UF particles has resulted in a large body of literature published in recent years, reporting on various aspects and characteristics of these particles (Morawska et al., 2008). Within the urban environment, the most significant sources of UF are various outdoor anthropogenic combustion sources, including vehicles (and other forms of transport), as well as industrial and power plants utilising fossil fuels (AQEG, 2005). Once the particles are emitted, they are quickly modified by a number of physical and chemical processes, of which knowledge remains incomplete. Current regulations address the amount of ambient particulate matter $(\mathrm{PM})$ as $\mathrm{PM}_{10}\left(D_{\mathrm{p}} \leq 10 \mu \mathrm{m}\right)$ and $\mathrm{PM}_{2.5}\left(D_{\mathrm{p}} \leq 2.5 \mu \mathrm{m}\right)$ expressed as a mass concentration of particles, and not particle number concentrations. It has been shown that in urban environments, the smallest particles make the highest contribution to the total particle number concentrations, but only a small contribution to particle volume or mass (Harrison et al., 2000). Recent toxicological studies have suggested that ultrafine particles, i.e., the fraction of fine particles below

Published by Copernicus Publications on behalf of the European Geosciences Union. 
$100 \mathrm{~nm}$ and the main component of ambient particles by number, are more toxic than coarser particles, per unit mass (Davidson et al., 2005; Seaton et al., 1995) and a recent epidemiological study in London (Atkinson et al., 2010) showed a strong association between particle number concentrations and both cardiovascular mortality and hospital admissions. Particles from road vehicles arise either from the exhaust, or from abrasion sources such as the wear of brakes, tyres and the road surface (Thorpe and Harrison, 2008).

In general, particles from vehicle exhaust can be divided into two broad categories, depending on the location of their formation. They can be formed in the engine or in the atmosphere after emission from the tailpipe (Shi and Harrison, 1999; Charron and Harrison, 2003). Particles formed within the engine ("soot" particles) are mostly submicrometre agglomerates of solid phase carbonaceous material ranging in size from 30 to $500 \mathrm{~nm}$. They may also contain metallic ash and adsorbed or condensed hydrocarbons and sulphur compounds (Schelle-Kreis et al., 2007). Particles formed by condensation in the diluting exhaust plume are generally in the size range below $30 \mathrm{~nm}$ and are formed as the hot exhaust gases are expelled from the tailpipe of a vehicle, creating large numbers of very small particles in the air. They are semi-volatile and consist mainly of hydrocarbons and hydrated sulphuric acid (Shi et al., 2000; Caravaggio et al., 2007). The conditions influencing the production of these semi-volatile nanoparticles and hence the shape of the particle size distributions, include dilution rate, dilution ratio and temperature. Recent work by Harrison et al. (2011a) has succeeded in using Positive Matrix Factorization to separate these two components from the particle size distribution.

As dilution increases downwind from the roadway, the concentration of organic vapours decreases, enhancing evaporation of the semi-volatile species from particle surfaces to re-establish equilibrium (Zhang et al., 2004). Volatility may explain the more rapid decay in particle concentration compared to the concentrations of non-labile PM species (such as elemental carbon) or gaseous pollutants (such as $\mathrm{CO}$ and $\mathrm{NO}_{\mathrm{x}}$ ) with increasing distance downwind from the roadway. However, Zhu et al. (2002) attributed the decreased particle number concentrations, and change in particle size distribution with increasing distance from the freeway, to both atmospheric deposition and coagulation. In the "road-to-ambient" process, dilution and condensation are dominant. Coagulation is slow compared to the dilution scale and hence unlikely to be important (Zhang and Wexler, 2004). Jacobson et al. (2005) accepted the model proposed by Zhang et al. (2004) where coagulation was not considered an important factor, and only condensation/evaporation and dilution were considered. Jacobson et al. (2005) proposed a new explanation suggesting small liquid nano-particles shed semi-volatile organics almost immediately upon emission. The shrinking of these nano-particles due to evaporation enhances coagulation of these smaller particles by over an order of magnitude. Lipsky and Robinson (2006) reported the effects of dilution on fine particle mass and the partitioning of semi-volatile organics in diesel exhausts. A large decrease in fine particle mass was observed with increased dilution. Emissions of elemental carbon did not vary with dilution, and the changes in fine particle mass were caused by changes in partitioning of semi-volatile compounds. Birmili et al. (2010) have demonstrated the semi-volatility of traffic particles of $<60 \mathrm{~nm}$ using a thermodenuder system. According to Ntziachristos et al. (2007), particle size distributions next to a freeway with high diesel traffic showed a bimodal distribution, with a nucleation mode below $40-50 \mathrm{~nm}$ and an accumulation mode peaking at $70-80 \mathrm{~nm}$ during all sampling hours. Currently the uncertainties in relation to vehicle emission factors for ultrafine particles from motor vehicles are still considerable - both for particle size ranges and for particle numbers. Particle formation in diluting engine exhaust depends strongly on meteorological factors (Charron and Harrison, 2003), and therefore an understanding of the evolution of nanoparticles in the urban environment must include all the factors described. Nonetheless, emission factors determined in dynamometer studies have been found to well reflect those estimated from roadside measurements (Beddows and Harrison, 2008).

Many studies have focused on the evolution of vehicular particles during advection away from the source, with very few studies focused on the vertical variations of particle number concentrations and size distributions. Li et al. (2007) reported that coagulation and dilution processes were the only factors causing changes to particle size distributions at vertical levels. In their data, size distributions differed between May and November. A finer mode was evident during the warmer month, but not seen in November. The different modes were attributed to nucleation processes of the semi-volatile matter emitted from vehicles. Kerminen et al. (2007) reported much smaller particle concentration dilution factors (1.1-1.3) with low wind speeds coupled with temperature inversions. Under such conditions, processes such as condensation, evaporation and coagulation are inefficient. Evaporation was given as a possible contributing cause for the decrease in 7-30 nm particle number concentrations for the sites more distant from the road. Other studies have determined the concentrations and size distributions of fine particles measured at roof level in an urban zone, showing an increase in particle concentration over the whole size range measured, but detected one hour later than the traffic peak at street level (Despiau and Croci, 2007). Particle number concentrations measured at street level were about 6.5 times higher than at rooftop. Conversely, rooftop particle number concentrations in the $5-30 \mathrm{~nm}$ size range increased with wind speed, whereas those for particles between 30 and $300 \mathrm{~nm}$ did not vary with wind speed (Kumar et al., 2009). To our knowledge there are no studies where remotely sensed profiles of urban turbulence were taken simultaneously with aerosol size distributions measured at different altitudes. Janhäll et al. (2006) reported Lidar data used to 
follow the break-up of the overnight inversion, but did not link that directly with particle size distributions measured at different heights.

The objective of the present paper is to report spatial variations in particles emitted from traffic and to observe the evolution of size distributions with distance and time by taking measurements simultaneously at three sites within the urban area of London. The aerosol measurements were also coupled with Doppler Lidar remote sensing measurements in order to study the effect of boundary layer dynamics upon the aerosol populations, by considering both measurements of mixing heights and atmospheric turbulence.

\section{Methods and data analysis}

\subsection{Sampling sites}

REPARTEE (Regents Park and Tower Environmental Experiment) was a multi-site study of aerosols and gases in the atmosphere of London (UK). More information can be found in Harrison et al. (2011b). During the REPARTEE field campaigns held for four weeks in both October 2006 and October/November 2007, measurements of particle number concentrations were made using condensation particle counters, and number size distributions using Scanning Mobility Particle Sizers deployed at locations in central London.

Sampling took place in 4 different locations (see Fig. 1):

- Marylebone Road (M. Road). This site is located on the kerbside of a major arterial route within the city of Westminster in London. The surrounding buildings form a street canyon. Traffic flows of over 70000 vehicles per day pass the site on 6 lanes with frequent congestion. This site is classified as a roadside site. The sample inlet is at a height of about $3 \mathrm{~m}$.

- BT Tower (BT Tower). This is the operational tower of British Telecom (60 Cleveland Street); the cylindrical tower stands $189 \mathrm{~m}$ above the ground. Measurements were taken from the 35th floor at about $160 \mathrm{~m}$ above ground level on a well ventilated balcony. The site is about $350 \mathrm{~m}$ south of M. Road.

- Inner Circle of Regents Park (R. Park). This is a major park within the city of London extending to 166 hectares (410 acres). The air sampling inlet was at $10 \mathrm{~m}$. The site is located away from local roads and is about $600 \mathrm{~m}$ north of M. Road, which is the nearest major highway. Meteorological, gas-phase and aerosol measurements were conducted from the top of a $10 \mathrm{~m}$ high tower constructed on site. To minimize sampling losses, air was drawn down a vertical sample pipe approximately $150 \mathrm{~mm}$ in diameter, which allowed air to be drawn from above the surrounding tree line. Air was sub-sampled from the main sample flow in an isokinetic manner through a $40 \mathrm{~mm}$ diameter stainless steel

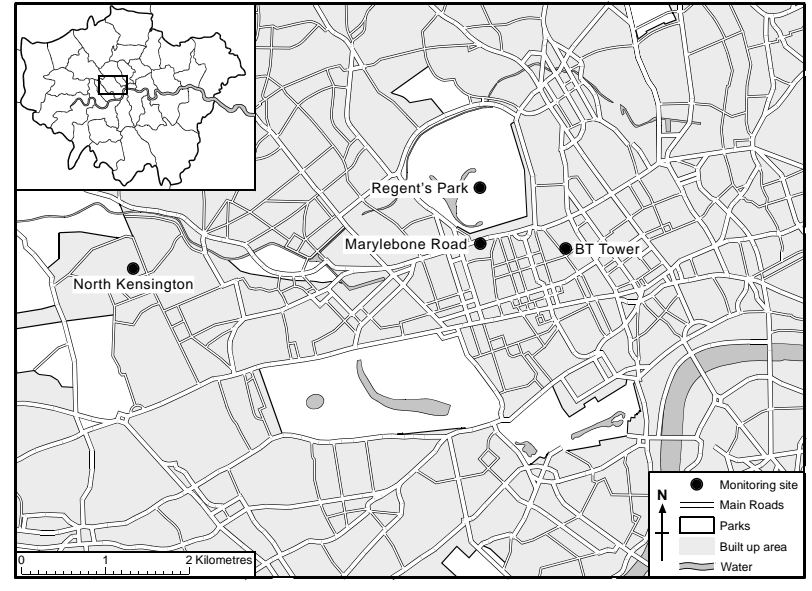

Fig. 1. Map showing sampling site locations. Inset map shows general location within central London.

pipe with a knife edge forward facing tip, and was taken via a gentle $90^{\circ}$ bend into the air conditioned mobile laboratory (Dall'Osto et al., 2009a, b).

- North Kensington (NK). This is sited in the grounds of Sion Manning School in St Charles Square, North Kensington, surrounded by a mainly residential area. The height of the inlet is approximately $3 \mathrm{~m}$. The site is classified as Urban Background by the UK automatic air quality network and is situated about $4 \mathrm{~km}$ east of the 3 sites described above. The pollution climate at this site has been analysed in detail by Bigi and Harrison (2010).

\subsection{Particle number concentrations}

Three of the sites (M. Road, BT Tower and NK) used the same type of particle counter (TSI Model 3022A; lower $50 \%$ cut-point $7 \mathrm{~nm}$ ) whilst the instrument in R. Park was a TSI 3776 (with a lower $50 \%$ cut-point at $2.5 \mathrm{~nm}$ ) which would lead to slightly higher readings on the latter instrument. The CPC data used in this paper were collected during the REPARTEE I field study (4-22 October 2006). Instrument deployments are summarised in Table 1.

\subsection{Aerosol size distributions measurements}

The size distribution data presented derive from the two REPARTEE campaigns, supplemented by additional data as outlined below. A combination of measurements from different years is used to investigate particle dynamics for sizes between $3 \mathrm{~nm}$ and $500 \mathrm{~nm}$. This is supplemented by a study of particles in the size range 20 to $500 \mathrm{~nm}$ from three measurement sites simultaneously. The former study allows the ultrafine mode to be characterised, the latter demonstrates that the different studies are comparable despite being conducted at different times. 
Table 1. Summary of instruments used in this study.

\begin{tabular}{|c|c|c|c|c|c|c|c|}
\hline \multirow[t]{2}{*}{ Site } & \multirow{2}{*}{$\begin{array}{l}\text { Height over } \\
\text { ground }(\mathrm{m})\end{array}$} & \multirow{2}{*}{$\begin{array}{l}\text { Traffic count } \\
\text { (vehicles/day) }\end{array}$} & \multirow[t]{2}{*}{ Time frame } & \multirow[t]{2}{*}{ Campaign } & \multicolumn{3}{|c|}{ Equipment } \\
\hline & & & & & $\mathrm{CPC}$ & Nano-SMPS & SMPS \\
\hline \multirow{3}{*}{ M. Road } & \multirow{3}{*}{3} & \multirow{3}{*}{80000} & 2003 & & - & $\begin{array}{l}\text { DMA TSI } \\
\text { 3080N + CPC } \\
\text { TSI3025 } \\
(5-184 \mathrm{~nm})\end{array}$ & - \\
\hline & & & 2006 & REPARTEE I & $\begin{array}{l}\text { TSI } 3022 \\
(7 \mathrm{~nm})\end{array}$ & - & - \\
\hline & & & 2007 & REPARTEE II & - & - & $\begin{array}{l}\text { DMA TSI } 3080 \\
+ \text { CPC TSI } \\
3776(14.6- \\
661.2 \mathrm{~nm})\end{array}$ \\
\hline \multirow[t]{2}{*}{ R. Park } & \multirow[t]{2}{*}{10} & \multirow[t]{2}{*}{-} & 2006 & REPARTEE I & $\begin{array}{l}\text { TSI } 3776 \\
(2.5 \mathrm{~nm})\end{array}$ & $\begin{array}{l}\text { DMPS Vienna } \\
\text { style + TSI } \\
\text { CPC } 3025 \text { and } \\
\text { TSI CPC } 3010 \\
(3-830 \mathrm{~nm})\end{array}$ & - \\
\hline & & & 2007 & REPARTEE II & - & - & $\begin{array}{l}\text { DMA TSI } \\
3080+\text { CPC } \\
3022 \mathrm{~A}(14.9- \\
673.2 \mathrm{~nm})\end{array}$ \\
\hline \multirow[b]{2}{*}{ BT Tower } & \multirow[b]{2}{*}{160} & \multirow[b]{2}{*}{-} & 2006 & REPARTEE I & $\begin{array}{l}\text { TSI } 3022 \\
(7 \mathrm{~nm}) \\
\end{array}$ & - & - \\
\hline & & & 2007 & REPARTEE II & - & $\begin{array}{l}\text { DMA TSI } 3085 \\
+ \text { CPC TSI } \\
3025(4.53- \\
159.5 \mathrm{~nm})\end{array}$ & $\begin{array}{l}\text { DMA TSI } 3080 \\
+ \text { CPC } 3022 \mathrm{~A} \\
(14.9-673.2 \mathrm{~nm})\end{array}$ \\
\hline $\begin{array}{l}\text { N. Kensing- } \\
\text { ton }\end{array}$ & 2.5 & - & 2006 & REPARTEE I & $\begin{array}{l}\text { TSI } 3022 \\
(7 \mathrm{~nm})\end{array}$ & - & - \\
\hline
\end{tabular}

\subsubsection{Non-simultaneous SMPS and nano-SMPS measurements}

- Data from M. Road were taken in October 2003 with a nano Scanning Mobility Particle Sizer (SMPS) system comprising a Model 3080N nanoclassifier and a Model 3025 Ultrafine Condensation Particle Counter (UCPC). This allowed the measurement of particles in the range 5-184 nm (Charron and Harrison, 2005).

- Data from the BT Tower were collected using two SMPS systems in October 2007 (REPARTEE-II). The first comprised a Model 3080 Electrostatic Classifier and a model 3022A Condensation Particle Counter (CPC). The classifier was configured to allow particles in the range 14.9-673.2 $\mathrm{nm}$ diameter to be counted and the sample time was $4 \min 30 \mathrm{~s}$ (scan $120 \mathrm{~s}+$ retrace $15 \mathrm{~s}$ $\times 2$ scans per sample). The second system comprised an
EC model TSI 3085 and CPC model TSI 3025 allowing counting in the particle size range $4.53-159.6 \mathrm{~nm}$. Sample time was $4 \mathrm{~min} 30 \mathrm{~s}$ (scan $120 \mathrm{~s}+$ retrace $15 \mathrm{~s} \times 2$ scans per sample).

- Size distribution measurements at R. Park were made using a Differential Mobility Particle Sizer (DMPS), covering the size range of about 3 to $830 \mathrm{~nm}$ diameter, during the month of October 2006 (REPARTEE-I). The DMPS consists of two "Vienna" style Differential Mobility Analysers (DMAs), as described by Williams et al. (2007), an ultrafine DMA (effective length $11 \mathrm{~cm}$ ) for particles in the size range $3.4-34 \mathrm{~nm}$ and a standard DMA (effective length $28 \mathrm{~cm}$ ) for particle sizes from $30-830 \mathrm{~nm}$. The aerosol particles were then counted using condensation particle counters (CPC). The ultrafine DMA was attached to a TSI 3025 ultrafine CPC (particle detection limit $50 \%$ at $3 \mathrm{~nm}$ ) and the standard 
DMA, to a TSI 3010 CPC (particle detection limit $50 \%$ at $10 \mathrm{~nm}$ ).

In summary, nano-SMPS data were available for the 3 different sites (M. Road, R. Park and BT Tower) for the same month of the year (October) but the measurements were taken in different field studies for each site (2003, 2006 and 2007 for M. Road, R. Park and BT Tower, respectively). The year to year variation in the particle size distributions collected at M. Road over the year 2000, 2001 and 2003 was found to be minimal (Charron and Harrison, 2003, 2005), allowing a comparison of particle size distributions taken at the same point during the same period (autumn) but in different years.

\subsubsection{Simultaneously deployed SMPS systems during REPARTEE II}

During REPARTEE II three SMPS systems were deployed simultaneously in the three different locations (road, background and tower sites), providing real time measurements of the particle size distributions at the 3 different sites. Two identical systems were used at the BT Tower and at R. Park (both classifier TSI 3080 and CPC 3022A), whilst the SMPS at the M. Road site used the same TSI 3080 EC but with a different CPC - model TSI 3776. The SMPS at R. Park and at BT Tower sites were sited together and inter-compared over a two-day period; they were found to agree very closely with each other, and to the SMPS at the M. Road site. The systems were compared both with and without inlet lines. Without an inlet, two SMPS agreed to within $10 \%$ over the range $15-250 \mathrm{~nm}$. With identical sampling lines, the nanoSMPS and SMPS systems agreed to within $25 \%$ over the range $15-160 \mathrm{~nm}$, with smaller differences over most of the range. Since it was not possible to operate the instruments with identical inlets at all sites, intercomparisons were also run with the actual inlet configurations and correction factors applied as inlet losses were site-dependent. Particle losses were calculated and used to correct the measured data. A summary of the different datasets explained in Sects. 2.3.1 and 2.3.2 is presented in Table 1.

\subsection{Organic carbon (OC) and elemental carbon (EC) measurements}

Continuous collection of $24 \mathrm{~h}$, midnight to midnight GMT $\mathrm{PM}_{2.5}$ and $\mathrm{PM}_{2.5-10}$ particles was carried out using two dichotomous Partisol-Plus Model 2025 Sequential Air Samplers, fitted with $\mathrm{PM}_{10}$ inlets. The instrument contains a virtual impactor and downstream flow controllers which separate the flow into fine and coarse fractions, at flow rates of $15.01 \mathrm{~min}^{-1}$ and $1.71 \mathrm{~min}^{-1}$, respectively from which particles were collected on quartz fibre filters (QM/A). The coarse particle sample was corrected for the collection of fine particles in the carrier flow. Sampling took place at R. Park and BT Tower from 2 October 2006 to 30 October 2006. Data capture was about $80 \%$ for simultaneous measurements at both sites. Elemental and organic carbon data were obtained by a Sunset Laboratory Thermal-Optical Carbon Aerosol Analyzer which uses thermal desorption in combination with optical transmission of laser light through the sample to speciate carbon (Sunset Laboratory Manual, 2000). The protocol is similar, but not identical to EUSAAR 2. Organic carbon is removed during an initial non-oxidizing temperature ramp from ambient to $700^{\circ} \mathrm{C}$ under a helium atmosphere, and then passes to a manganese dioxide oxidizing oven where it is converted to carbon dioxide, which is mixed with hydrogen and converted to methane over a heated nickel catalyst. The methane is subsequently measured using a flame ionization detector (FID). A second temperature ramp from $550^{\circ} \mathrm{C}$ to $850^{\circ} \mathrm{C}$ is then initialized with the carrier gas switched to a helium/oxygen mixture, under which elemental carbon and pyrolysis products are oxidized and carried through the system and measured in the same manner as the organic carbon. A laser is used to monitor the light transmission through the filter during the analysis, which determines a split point that separates the elemental carbon formed by charring during the initial non-oxidizing temperature ramp from the elemental carbon that was originally in the sample. The split point is the point in time when the laser signal measured during the oxidizing stage equals the initial laser signal. Both external (sucrose solution) and internal (methane gas) carbon standards are used for FID calibration.

\subsection{SMPS clustering analysis}

The 3 SMPS systems deployed simultaneously during REPARTEE-II (17 October 2007 to 9 November 2007) generated approximately 7000 SMPS size distributions at $5 \mathrm{~min}$ resolution at each site. These size distributions were averaged over $1 \mathrm{~h}$ periods reducing their number from about 20000 to 1567 , which were subsequently normalised by their vector-length and cluster analysed (Beddows et al., 2009). The same size distributions were averaged also over $6 \mathrm{~h}$ intervals (00:00-06:00, 06:00-12:00, 12:00-18:00, 18:00-00:00) reducing their number to 259 and these results are presented elsewhere (Beddows et al., 2009). The cluster analysis differentiated the spectra into a small number of size distributions based upon similarities in their size distributions. The objective of this paper required a higher time resolution $(1 \mathrm{~h})$ in order to see the evolution of UF particles in the atmosphere. The Dunn-Index for the results of the K-means analysis for different cluster numbers showed a clear maximum for 22 clusters, some of which belonged only to specific sampling sites and to specific times of the day. One advantage of this clustering method over providing an average of aerosol size distributions is that it does provide a specific number of size distributions which can be compared across different time periods (Beddows et al., 2009). The intensive observations of aerosol size distributions were used with trace gas data and measurements of boundary layer dynamics to quantify 
the variability in urban aerosols caused by both chemical and meteorological processes.

\subsection{Doppler Lidar description and height estimation methods}

The Doppler Lidar permits the detection of the boundary layer (BL) top, mixing height and aerosol layer top with a vertical resolution within a few tens of metres and a temporal resolution in the range of seconds to minutes. Further Lidar results and analysis from the REPARTEE II campaign are more fully described in Barlow et al. (2011). The instrument was a Halo Photonics 1.5 micron scanning Doppler Lidar (provided by the Facility for Ground-based Atmospheric Measurements (FGAM)) and operated by the University of Salford; a full description of the instrument is given in Pearson et al., 2009). It was installed in the car park of the University of Westminster on the M. Road directly adjacent to the air sampling station and was running continuously for three weeks between 24 October and 14 November 2007. Due to the proximity and height of the neighbouring buildings, the Lidar was restricted to making only vertical stare measurements i.e. directly upwards. During this study the Lidar was set to have a vertical resolution of $30 \mathrm{~m}$ and was focussed at $2 \mathrm{~km}$ in order to maximise the signal from the boundary layer. This resulted in a total of 66 measurement range gates. The Lidar returns a measurement of backscatter and a Doppler velocity measurement every $4 \mathrm{~s}$, from which turbulent statistics in the boundary layer can be calculated. The vertical velocity variance is used to calculate the mixing height, $z_{\mathrm{MH}}$, i.e. the height to which aerosols are mixed from the surface vertically due to turbulent transport (Siebert et al., 2000). From the Lidar measurements, the mixing height was defined as the height in the boundary layer up to which a threshold of $\sigma_{w}^{2}>0.1 \mathrm{~m}^{2} \mathrm{~s}^{-2}$ is met ( $\sigma_{w}^{2}$ is the variance of the vertical wind velocity). This threshold was determined by examining the sensitivity of derived mixing heights to the chosen threshold value until a reasonable (i.e. physically realistic) range of mixing heights was obtained. It is recognized that this choice is somewhat arbitrary, which is explored in Barlow et al. (2011). A second height is determined through examination of the gradient in the backscatter profile. At the boundary between two layers of differing aerosol concentration, there will be a sharp change in the gradient of the backscatter. The lowest, ground-based aerosol layer can be detected by finding the first significant negative gradient in the backscatter looking from the surface upwards. A significant negative gradient in the backscatter was defined quantitatively as less than -0.03 (arbitrary units). Again, this criterion was found by examining the sensitivity of the derived aerosol layer depth until a satisfactory range of heights were found. Herein, this height is referred to as $z_{\text {AER }}$. Further details of the methods for detecting different layer heights are given in Barlow et al. (2011).

\subsection{Gas measurements and meteorological data}

Measurements of trace gases $\left(\mathrm{NO}, \mathrm{NO}_{2}\right.$ and $\left.\mathrm{O}_{3}\right)$ and meteorological variables (relative humidity, $\mathrm{RH}$ and temperature, $T$ ) used for the ground site were taken from the North Kensington (NK) site (data taken from the UK Air Quality Archive: www.airquality.co.uk). In each case $\mathrm{O}_{3}$ was measured by UV absorption, NO by chemiluminescence and $\mathrm{NO}_{2}$ by thermal conversion (heated Mo catalyst)/chemiluminescence; the $\mathrm{NO}_{2}$ signal may therefore be subject to interferences from other $\mathrm{NO}_{\mathrm{y}}$ compounds (Dunlea et al., 2007). Meteorological variables were also measured at the BT Tower using a Vaisala WXT510 weather station located on top of the tower at $190 \mathrm{~m}$. In both cases, measurements were continuous throughout the campaigns.

\section{Results}

\subsection{Nano particle evolution}

Figure 2 shows the average diurnal pattern of particle number concentrations at all four sites. This shows a clear gradient in number concentrations from M. Road, peaking at around $100 \times 10^{3} \mathrm{~cm}^{-3}$, to R. Park (around $38 \times 10^{3} \mathrm{~cm}^{-3}$ ), to North Kensington $\left(25 \times 10^{3} \mathrm{~cm}^{-3}\right)$ and the BT Tower $\left(9 \times 10^{3} \mathrm{~cm}^{-3}\right)$. The high ratio in particle number concentrations between the ground-based sites and the BT Tower is unlikely to be explained by dispersion processes alone. The average ratio for all hours throughout the entire campaign for particle number concentration between the BT Tower and North Kensington, (which used identical samplers) was $0.39 \pm 0.12$ (s.d.) whereas the ratio of elemental carbon in $\mathrm{PM}_{2.5}$ particles between the BT Tower and R. Park averaged $0.57 \pm 0.10$ (Table 2) - obtained from 24-h Partisol samples. A regression of the EC concentrations at the BT Tower and R. Park sites showed a relationship of BT Tower $=0.66$ R. Park $-0.27 \mu \mathrm{g} \mathrm{m}^{-3}\left(R^{2}=0.92\right)$. Recent work (Harrison and Yin, 2008) has shown that elemental carbon is an excellent tracer of diesel exhaust emissions and it is a species with a relatively long atmospheric lifetime which is a useful tracer of ground-level urban emissions. The data demonstrate a major loss of particle number on the Tower relative to groundlevel measurements in the footprint region, taking account of elemental carbon as passive tracer. Interpretation of these data is limited by lack of knowledge of the background air into which London emissions are mixing, and unfortunately corresponding measurements are not available from the Harwell rural site outside of London at this time.

Further evidence on this phenomenon comes from a comparison of particle size distributions at three sites (Fig. 3), constructed from data collected as outlined in Sect. 2.3. In further measurements, in which three nearly identical SMPS systems were deployed concurrently at the three locations (DMA TSI 3080 and CPC TSI 3022A or 3776, size range 
Table 2. Relationship of particle number count from CPC to elemental carbon concentrations for three sites.

\begin{tabular}{lllll}
\hline Site & CPC model & $\begin{array}{l}\mathrm{N} \\
\left(\mathrm{cm}^{-3}\right)\end{array}$ & $\begin{array}{l}\mathrm{PM}_{2.5} \mathrm{EC} \\
\left(\mu \mathrm{g} \mathrm{m}^{-3}\right)\end{array}$ & $\begin{array}{l}\mathrm{CPC} \text { counts/PM} \\
\text { mass }\left(\mathrm{cm}^{-3} \mathrm{~m}^{3} \mu \mathrm{g}^{-1}\right)\end{array}$ \\
\hline BT Tower & 3022 & 12550 & 1.1 & 11400 \\
& $(>7 \mathrm{~nm})$ & \pm 1300 & \pm 0.6 & \pm 3800 \\
North Kensington & 3022 & 20500 & 1.4 & 14700 \\
& $(>7 \mathrm{~nm})$ & \pm 4000 & \pm 0.6 & \pm 3300 \\
R. Park & 3776 & 29200 & 1.5 & 19450 \\
& $(>2.5 \mathrm{~nm})$ & \pm 5000 & \pm 0.6 & \pm 6745 \\
\hline
\end{tabular}

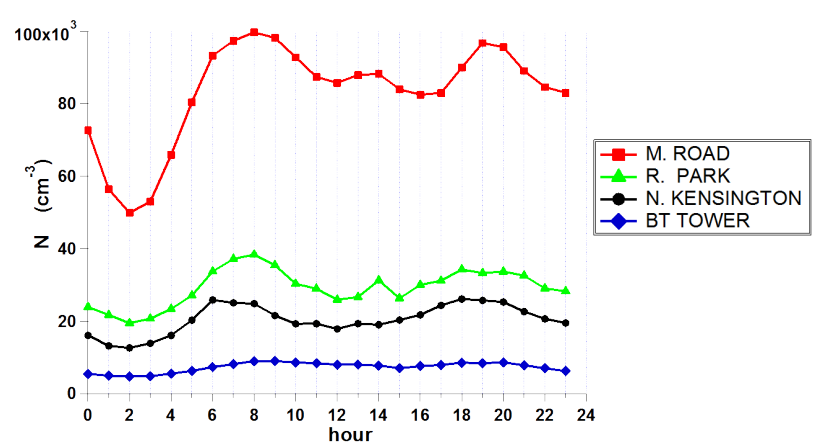

Fig. 2. Average particle number concentrations $\left(\mathrm{cm}^{-3}\right)$ as a function of time of day for M. Road, R. Park, North Kensington and BT Tower. All measurements were taken with the same instruments (CPC TSI 3022A) apart from R. Park (TSI 3776). All the data are from the REPARTEE I field study.

15.1-661 nm) with matched inlet systems over the same time period (October 2007) the same trend reported in Fig. 3 (see Sect. 3.2) was seen, but did not extend to the smaller particle sizes. More details on this independent study are given in the next section.

The size distribution measured at M. Road is typical of roadside and on-road number size distributions, peaking between 20 and $30 \mathrm{~nm}$ diameter (Charron and Harrison, 2003; Ronkko et al., 2007). In contrast, data from the R. Park site show a mode which has shifted downwards to below $10 \mathrm{~nm}$ diameter together with some overall loss of area under the curve representing a loss of total particle number. In contrast, the data from the BT Tower show a minor mode at around $20 \mathrm{~nm}$, whilst the major mode is in the region of $100 \mathrm{~nm}$ diameter typical of the involatile graphitic particles in engine exhaust, and accumulation mode particles from other sources. This mode is also visible as a shoulder in the other size distributions. When a curve-fitting programme is used to disaggregate these size distributions into a number of lognormal distributions and the M. Road data are compared with R. Park (Fig. 4), both datasets show the mode at 40-60 nm and a mode at around $15-20 \mathrm{~nm}$, which is much reduced in

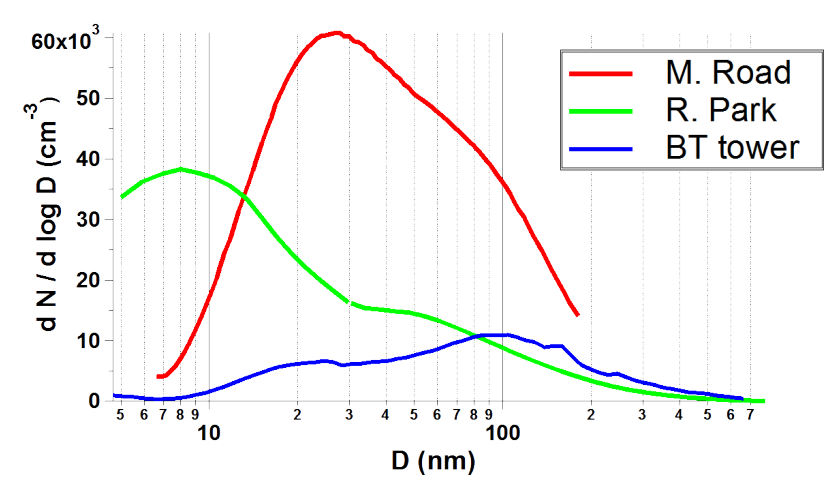

Fig. 3. Average particle size distributions (mobility diameter, nm) at M. Road, R. Park and BT Tower.

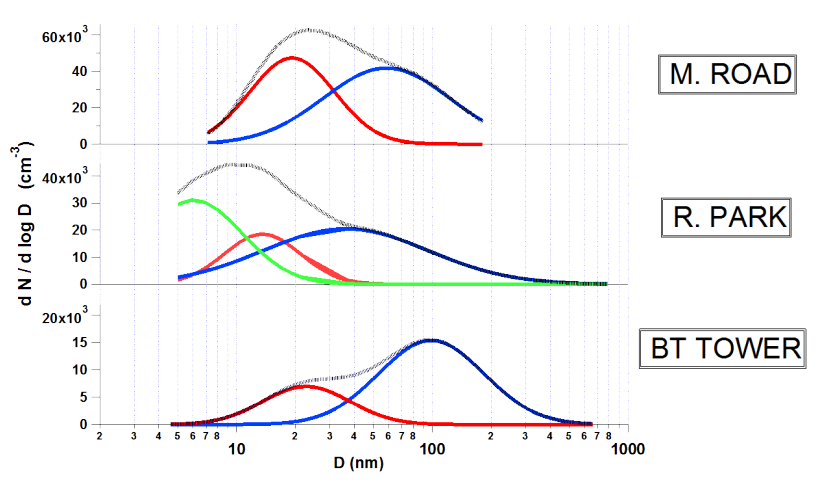

Fig. 4. Measured size distributions from Fig. 3 expressed as combinations of component log normal distributions. Please note different $y$-axes for the 3 different sites $\left(60,40\right.$ and $20000 \mathrm{~cm}^{-3}$ for M. Road, R. Park and BT Tower, respectively).

the R. Park data. At R. Park but not M. Road, a further mode peaking at around $6 \mathrm{~nm}$ was observed. We believe this arises from the evaporation of particles initially in the $20 \mathrm{~nm}$ diameter mode during advection into the Park, and is consistent with the involatile particle core measurements for diesel exhaust reported by Ronkko et al. (2007) and Kirchner et 

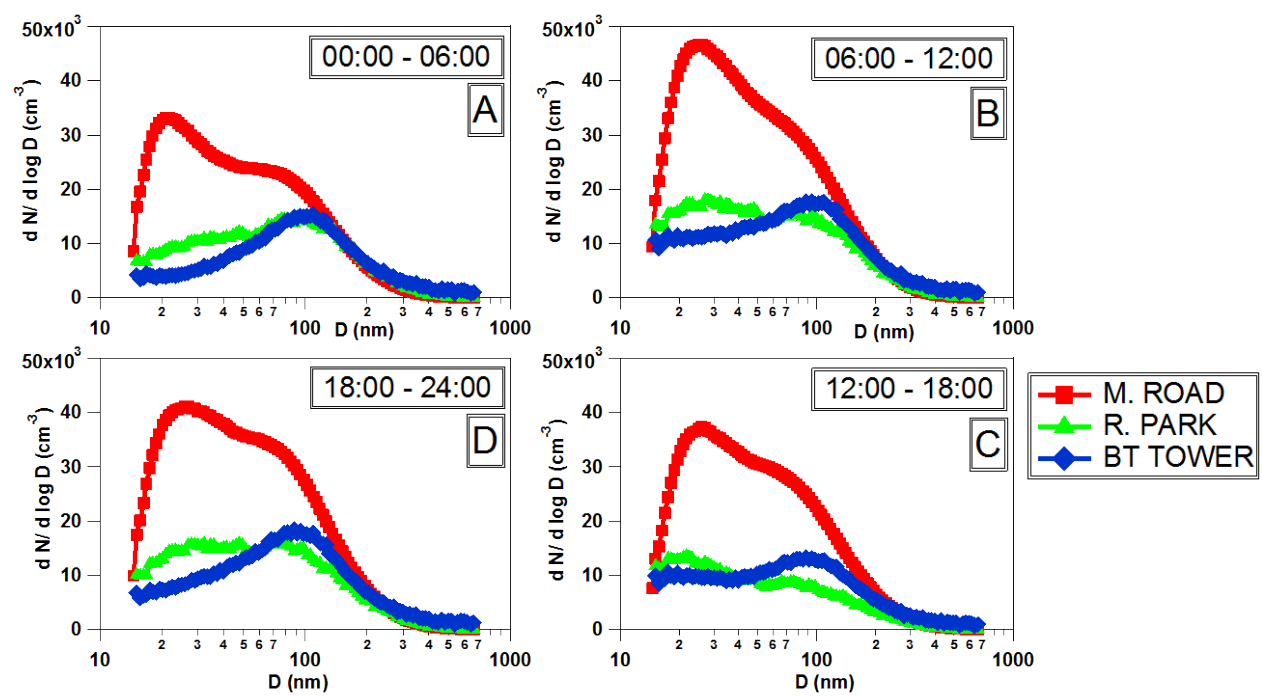

Fig. 5. Average SMPS size distributions for 3 different sites (M. Road, R. Park and BT Tower) taken simultaneously during the REPARTEE-II field study. Data are average for the 6 hours time period at 00:00-06:00 (A), 06:00-12:00 (B), 12:00-18:00 (C) and 18:00-24:00 (D).

al. (2009). Average data from the BT Tower show modes at around $100 \mathrm{~nm}$ (non-volatile traffic particles and long-range transported secondary components), and $25 \mathrm{~nm}$, which we interpret as traffic particles which are seen only during daytime (Fig. 5). The sub-10 nm mode at R. Park could conceivably arise from localised nucleation processes, but the diurnal pattern gave no strong support to this concept, and fluctuations in particle concentrations correlated with $\mathrm{NO}_{\mathrm{x}}$ and black carbon indicating a traffic source.

\subsection{Simultaneous SMPS measurements during REPARTEE II}

Figures 3 and 4 were obtained with aerosol size distribution measurements taken in London during the same month of different years (October 2003, October 2006 and October 2007). During REPARTEE II, three SMPS systems were deployed simultaneously at 3 sites in London providing aerosol size distributions in the range between $15 \mathrm{~nm}$ and $550 \mathrm{~nm}$. The data shown in Figs. 5 and 6 demonstrate how the exclusion of particles below $15 \mathrm{~nm}$ in diameter results in an incomplete description of the nanoparticle evolution towards smaller sizes, simply because the mode below $10 \mathrm{~nm}$ seen at R. Park is totally missed. Nevertheless, the 3 SMPS systems deployed simultaneously in London during REPARTEE II help to support the conclusions derived from Fig. 3 as they provide measurements taken simultaneously, hence overcoming the weakness that the previous dataset combines measurements from different campaigns. Figure 5 shows clockwise the average size distributions from REPARTEE II at the M. Road, R. Park and BT Tower sites for the $6 \mathrm{~h}$ time periods at 00:00-06:00 (A), 06:00-12:00 (B), 12:0018:00 (C) and 18:00-24:00 (D), respectively. As expected the M. Road site presents the highest aerosol particle number concentration, with the modes at about $20-30 \mathrm{~nm}$ and $60-$ $80 \mathrm{~nm}$ as already described in Fig. 3 and elsewhere (Charron and Harrison, 2003). The aerosol size distributions at the R. Park site for the warm part of the day (Fig. 5c) show a shift of the mode at $20 \mathrm{~nm}$ towards smaller sizes, confirming the finding of Fig. 3. The average size distributions from the BT Tower site do not change dramatically, other than for a higher number of particles below $50 \mathrm{~nm}$ during daytime (Fig. 5b and 5c). Whilst Fig. 5 is important to indicate the variability across the three different sites for the same simultaneous sampling time, Fig. 6 shows the variability of the aerosol size distributions at the same site but for different parts of the day ( $6 \mathrm{~h}$ intervals). Figure 6a shows the higher particle number concentrations for rush hour periods (green and black lines) detected at the M. Road site. Figure $6 \mathrm{~b}$ representing R. Park shows the overall lowest aerosol particle number loading for the nighttime (red line). The rush hour time intervals (green and black) are characterised by a higher number of particles below $50 \mathrm{~nm}$ reflecting the traffic emissions detected also at the R. Park site. Interestingly, during the warmest part of the day (blue line, 12:00-18:00) the smaller mode at about $20-30 \mathrm{~nm}$ is observed to reduce from about $27 \mathrm{~nm}$ to $18 \mathrm{~nm}$. Although limited to the interval 15$650 \mathrm{~nm}$, these findings support those described in Figs. 3 and 4 where nano-SMPS systems were used and shows a shift of particles towards smaller sizes presumably due to evaporative loss of material as it is advected from the traffic source. The average diurnal temperature range in REPARTEE II was $8^{\circ} \mathrm{C}$ for hourly data.

Figure $6 \mathrm{c}$ shows the average size distributions for the 4 different time periods at the BT Tower site. A higher particle number concentration for particles smaller than $25 \mathrm{~nm}$ can 

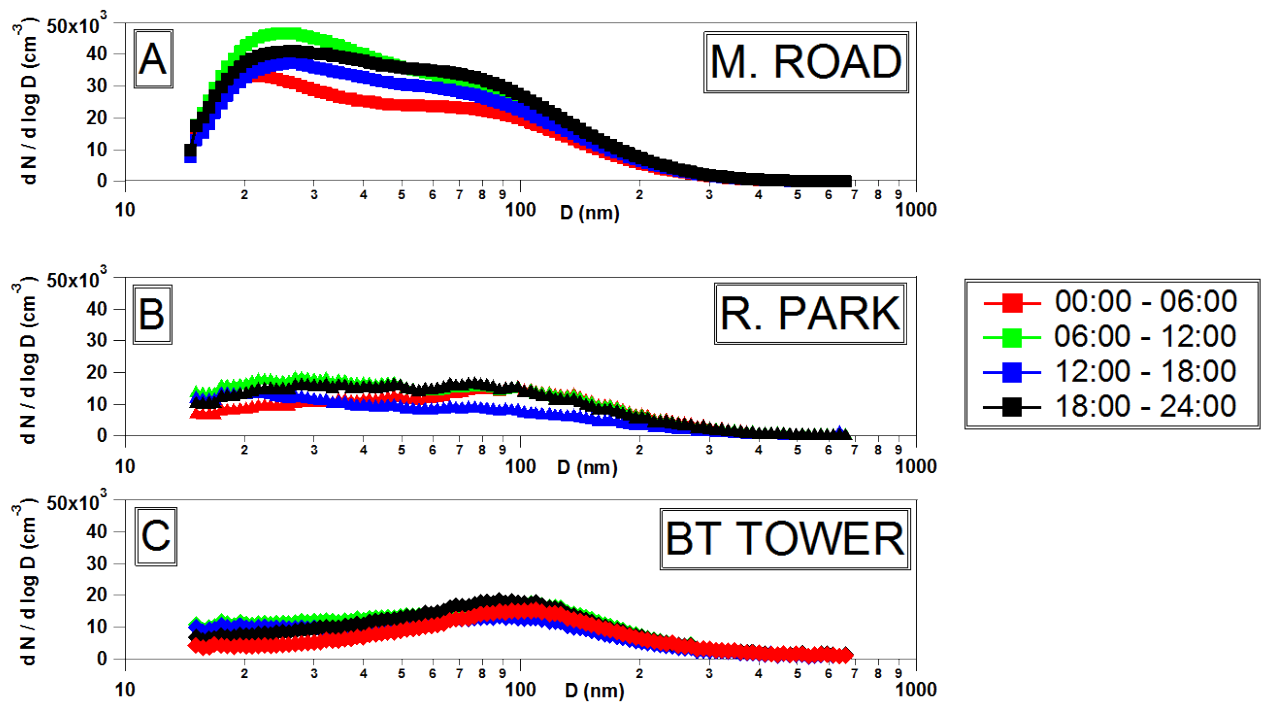

Fig. 6. Same size distributions as in Fig. 5, re-drawn for comparison. Average SMPS size distributions taken simultaneously during the REPARTEE-II field study at $6 \mathrm{~h}$ time period at 00:00-06:00, 06:00-12:00, 12:00-18:00 and 18:00-24:00 for (A) M. Road, (B) R. Park and (C) BT Tower.

clearly be seen for daytime periods (06:00-18:00, blue and green lines) in comparison to the nighttime periods (18:0006:00, red and black lines). This clearly reflects the fact that small particles emitted within London are transported vertically to the height of the tower more efficiently during the day than at night when mixing is suppressed and the traffic emissions are reduced. Martin et al. (2009) measured total particle number flux $\left(D_{\mathrm{p}}>10 \mathrm{~nm}\right)$ at the BT Tower during REPARTEE I and found strong diurnal cycles with pronounced weekend versus weekday differences which can be linked to traffic activity. The present study not only reports total particle number concentrations but also provides unique aerosol size distribution data illustrative of the dynamics of the aerosol populations across different sites. An in-depth analysis of the evolution of the size distributions of particles detected at the BT Tower site, coupled with Doppler Lidar measurements is given in the next section.

\subsection{The effect of boundary layer dynamics on the aerosol size distributions over London}

The Lidar measurements give high-resolution information about the structure of the boundary layer and the turbulence and aerosols present within it. Various different heights are defined in Barlow et al. (2011): in this work we have used the convective mixing layer height, $z_{\mathrm{MH}}$. This is derived from the variance of the vertical wind velocity $\left(\sigma_{w}^{2}\right)$, with the mixing layer top being defined as the height at which $\sigma_{w}^{2}$ falls to $<0.2 \mathrm{~m}^{2} \mathrm{~s}^{-2}$. The mean variance of the vertical wind velocity $\left(\sigma_{w}^{2}\right)$ between $100-250 \mathrm{~m}$ was also calculated over half hour periods and is taken as a surrogate for the turbulence strength. For this study, the UBL heights and the $\sigma_{w}^{2}$ values were averaged to one hour resolution. The size distribution data were disaggregated according to whether $z_{\mathrm{MH}}$ was below or above the height of sampling on the tower $(160 \mathrm{~m})$. Hence all Lidar gates of $150 \mathrm{~m}$ and below were combined into the former category and those of $180 \mathrm{~m}$ above into the latter. Data from the 150-180 m Lidar gates were not used. Figure 7 shows the average nano-SMPS size distributions (5$140 \mathrm{~nm}$ ) collected during REPARTEE II at the BT Tower site for different values of two variables obtained from the Lidar.

The data in Fig. 7 are disaggregated as follows: average nano-SMPS size distributions for BL above $180 \mathrm{~m}$ $\left(z_{\mathrm{MH}}>180 \mathrm{~m}\right.$, red line $)$ and BL below $150 \mathrm{~m}\left(z_{\mathrm{MH}}<150 \mathrm{~m}\right.$, black line) for all the Lidar datapoints. Furthermore, the data for BL $>180 \mathrm{~m}$ were divided into periods of high turbulence $\left(\sigma_{w}^{2}>0.5 \mathrm{~m}^{2} \mathrm{~s}^{-2}\right.$; green line) and low turbulence $\left(\sigma_{w}^{2}<0.5 \mathrm{~m}^{2} \mathrm{~s}^{-2}\right.$; blue line). When comparing size distributions for the BL above and below the BT Tower sampler, there is an enhancement of particles smaller than $50 \mathrm{~nm}$ for the former case. This is even more evident when considering periods of high turbulence relative to the periods of lower turbulence (blue and green lines respectively).

Under conditions when the BT Tower sampler was above the mixing height, the greatest abundance of accumulation mode particles accompanied the lowest abundance of sub$50 \mathrm{~nm}$ particles. A deep boundary layer and high turbulence is associated with the lowest abundance of accumulation mode particles and the highest numbers of sub-50 nm particles. The $\mathrm{NO}_{\mathrm{x}}$ data (Table 3 ) also show slightly higher mean concentrations at the BT Tower site with a shallow boundary layer $(<150 \mathrm{~m})$ than when the boundary layer is deeper $(>180 \mathrm{~m})$. The fact that enhanced mixing leads both to an 
Table 3. Concentrations (mean \pm s.d.; ppb) of $\mathrm{NO}_{\mathrm{x}}$ and $\mathrm{O}_{3}$ at ground level (NK) and aloft on the BT Tower as a function of mixed layer depth (BL) and turbulence level (low is $\sigma_{w}^{2}<0.5 \mathrm{~m}^{2} \mathrm{~s}^{-2}$; high is $\sigma_{w}>0.5 \mathrm{~m}^{2} \mathrm{~s}^{-2}$ ). Units are in ppb for gas measurements, degrees Celsius for temperature (Temp) and \% for Relative Humidity (RH).

\begin{tabular}{l|ll|ll|ll|ll}
\hline & \multicolumn{3}{|c|}{$\mathrm{NO}_{\mathrm{x}}$} & \multicolumn{2}{c|}{$\mathrm{O}_{3}$} & \multicolumn{2}{c|}{ Temp. } & \multicolumn{2}{c}{$\mathrm{RH}$} \\
\cline { 2 - 10 } & Ground & Tower & Ground & Tower & Ground & Tower & Ground & Tower \\
\hline $\mathrm{BL}<150 \mathrm{~m}$ & 81 & 22 & 4 & 16 & 9.4 & 7.8 & 84 & 80 \\
& \pm 75 & \pm 16 & \pm 7 & \pm 7 & \pm 2.4 & \pm 1.8 & \pm 12 & \pm 10 \\
\hline $\mathrm{BL}>180 \mathrm{~m}$ & 35 & 21 & 11 & 17 & 12.3 & 8.5 & 76 & 81 \\
& \pm 26 & \pm 15 & \pm 8 & \pm 7 & \pm 2.7 & \pm 2 & \pm 11 & \pm 10 \\
\hline $\mathrm{BL}>180 \mathrm{~m}$ & 51 & 26 & 5 & 13 & 10.9 & 7.7 & 81 & 84 \\
$\sigma_{w}^{2}<0.5$ & \pm 28 & \pm 19 & \pm 7 & \pm 7 & \pm 2.3 & \pm 1.8 & \pm 10 & \pm 9 \\
\hline $\mathrm{BL}>180 \mathrm{~m}$ & 28 & 19 & 14 & 18 & 13.0 & 8.9 & 73 & 80 \\
$\sigma_{w}^{2}>0.5$ & \pm 20 & \pm 12 & \pm 7 & \pm 6 & \pm 2.7 & \pm 2 & \pm 10 & \pm 10 \\
\hline$\sigma_{w}^{2}<0.5$ & 74 & 25 & 3 & 14 & 10.2 & 7.7 & 82 & 82 \\
& \pm 57 & \pm 18 & \pm 6 & \pm 7 & \pm 2.4 & \pm 1.8 & \pm 10 & \pm 9 \\
\hline $0.5<\sigma_{w}^{2}<1.0$ & 30 & 20 & 13 & 18 & 11.9 & 8.8 & 76 & 80 \\
& \pm 22 & \pm 12 & \pm 8 & \pm 6 & \pm 2.5 & \pm 1.8 & \pm 10 & \pm 10 \\
\hline$\sigma_{w}^{2}>1.0$ & 16 & 10 & 21 & 25 & 13.0 & 8.9 & 73 & 80 \\
& \pm 10 & \pm 6 & \pm 6 & \pm 6 & \pm 3.8 & \pm 2.9 & \pm 13 & \pm 12 \\
\hline
\end{tabular}

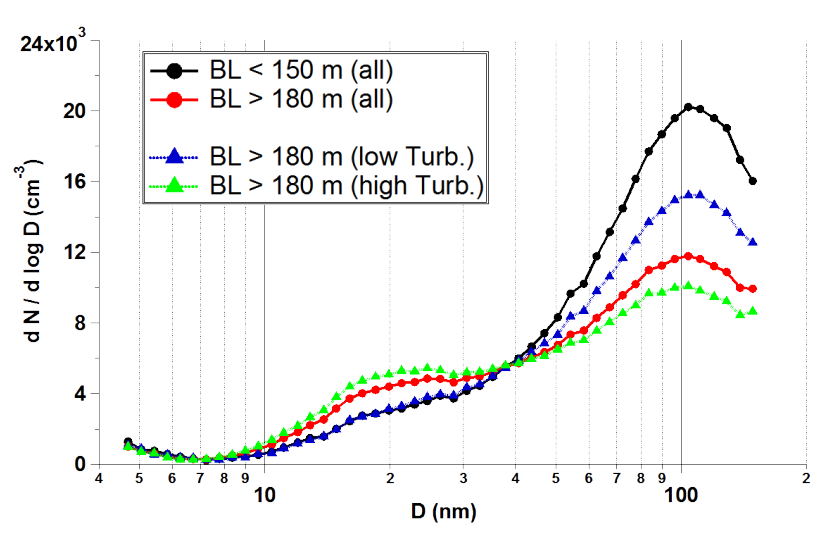

Fig. 7. Average nano-SMPS size distributions at the BT Tower site for periods of: UBL height below the BT Tower sampling height $(<150 \mathrm{~m})$; high UBL height $(>180 \mathrm{~m})$; low $\sigma_{w}^{2}\left(<0.5 \mathrm{~m}^{2} \mathrm{~s}^{-2}\right)$ and high $\sigma_{w}^{2}\left(>0.5 \mathrm{~m}^{2} \mathrm{~s}^{-2}\right)$. Measurements of UBL height and $\sigma_{w}^{2}$ were derived from the Lidar, using $z_{\mathrm{MH}}$ as the measure of UBL depth.

increase in sub-50 $\mathrm{nm}$ particles and a decrease in the largersized accumulation mode peak is at first sight surprising. However, the Lidar backscatter data (Barlow et al., 2011) show a decrease in light scattering aerosol (close in size to $1.5 \mu \mathrm{m}$, the wavelength of the Lidar) with height above the top of the mixing height, and hence enhanced mixing associated with a deepening boundary layer not only carries polluted air from below (with much enhanced sub-50 nm parti- cle concentrations, but comparable accumulation mode levels), but also cleaner air from above leading to the reduction in accumulation mode concentrations. This interpretation is supported by the $\mathrm{NO}_{\mathrm{x}}$ data in Table 3 which show a decrease as the mixing height extends above the height of the sampler. A contribution of nucleation processes taking place aloft to the enhancement of sub- $20 \mathrm{~nm}$ particles at the BT Tower cannot be entirely ruled out, and similar processes have been suggested by Wehner et al. (2010). Kumar et al. (2009) attributed the production of nucleation mode particles (and also a nucleation event) at rooftop level to both the production of new particles through gas-to-particle conversion and photochemically induced nucleation, since conditions were found to be favourable for both processes. Our data give no obvious indication of new particle formation from nucleation processes, but our earlier work in a UK city has shown this to be a relatively infrequent occurrence at ground-level (Alam et al., 2003). The fact that air at the sampling height on the BT Tower retains high concentrations of $\mathrm{NO}_{\mathrm{x}}$ and accumulation mode particles but is heavily depleted in sub- $-50 \mathrm{~nm}$ particles when isolated from the source below, is a clear indication that the lifetime of surface-derived sub- $50 \mathrm{~nm}$ particles is short compared to that of $\mathrm{NO}_{\mathrm{x}}$ and larger particles.

Complementary physical and chemical data for the periods used for generating Fig. 7 can also be seen in Table 3, where gas measurements and basic meteorological parameters are given for the 4 different scenarios. More information on other parameters, including wind speed, can be found in Barlow et al. (2011). The difference in temperature values 
between the ground site (NK) and the BT Tower site are higher in periods with high $\sigma_{w}^{2}$ and deep boundary layer. This is expected, as the temperature gradient between the ground level and the air creates much of the turbulence through convection.

Concentrations of ozone were normally higher at the BT Tower in comparison to the ground sites; in contrast higher values of $\mathrm{NO}_{\mathrm{x}}$ were found at the ground sites. Again, this is expected as nitrogen oxides are emitted by traffic. For similar values of $z_{\mathrm{MH}}$, a greater dispersion of $\mathrm{NO}_{\mathrm{x}}$ (lower concentrations) can be seen at the North Kensington background site with higher turbulence levels. For high turbulence values the differences between the tower and the ground sites were found to be much reduced (in comparison to low turbulence values) reflecting more efficient mixing. Strong downward fluxes of ozone were observed during the experiment $(\mathrm{Ne}-$ mitz et al., 2011).

Further evidence for the evaporation and the dispersion of traffic related particles is derived by comparing the Lidar measurements with the SMPS data clustered according the method described by Beddows et al. (2009). Data from around 7000 SMPS size distributions were pooled from all three sites from the REPARTEE II campaign. Eleven of the 22 SMPS size distribution clusters obtained were found to occur mainly at the BT Tower site, the others were associated with size distributions collected at the M. Road and R. Park sites. By comparing clusters of specific size distributions with the hourly averaged $\sigma_{w}^{2}$ (taken at the Lidar height interval $100-250 \mathrm{~m}$, i.e. around the sampling height on the tower), we can associate an average value of turbulence to a specific SMPS size distribution obtained by clustering the measurements taken at the BT Tower. Figure 8 shows the 11 SMPS clusters describing the SMPS size distributions sampled at the BT Tower site. Two main modes can be seen: the first at about $80-120 \mathrm{~nm}$ representing the accumulation mode and a second, peaking at about $20-30 \mathrm{~nm}$. The two most diverse clusters are probably cluster 14 and cluster 6 , with enhanced modes at $80-120 \mathrm{~nm}$ and $20-30 \mathrm{~nm}$, respectively. The smaller mode can also be seen in Fig. 3, and is attributed to traffic related particles seen only during daytime. Clusters 11 and 10 contain instead about the same abundance of both aerosol size modes. The legend of Fig. 8 also reports the average values for $\sigma_{w}^{2}$ for each of the 11 SMPS clusters. The clusters with the highest mode at $20-30 \mathrm{~nm}$ are the ones associated with the higher turbulence (i.e. cluster 6 for example presents an average $\sigma_{w}^{2}$ of $1.26 \mathrm{~m}^{2} \mathrm{~s}^{-2}$ ). By taking the total number of particles below $30 \mathrm{~nm}$ of each SMPS cluster and regressing it upon the average values of turbulence, an $R^{2}$ value of 0.86 was calculated (Fig. 8). The parameter $\sigma_{w}^{2}$ is a surrogate for turbulence strength and therefore for the transport time between emission at ground level and observation at the measurement height, which dictates how much the emissions have aged. To our knowledge, these are the first results published in the literature showing a clear linkage between turbulence values obtained by Lidar and simultane- ous SMPS measurements taken above a city. Figure 8 also shows that cluster 6 and cluster 7 (with the highest values of average $\sigma_{w}^{2}$ of 1.26 and $0.93 \mathrm{~m}^{2} \mathrm{~s}^{-2}$, respectively) exhibit the smaller mode shifted towards the smallest detectable sizes below $19 \mathrm{~nm}$. In contrast, clusters characterized by a lower $\sigma_{w}^{2}$ (cluster 1 and cluster 11 , for example with $\sigma_{w}^{2}$ of 0.78 and $0.51 \mathrm{~m}^{2} \mathrm{~s}^{-2}$, respectively) show a mode above $25 \mathrm{~nm}$. Particle size spectra collected over the same period at the rural Harwell site to the west of London showed appreciably lower particle numbers (maximum in average $d N / d \log D$ of below $6 \times 10^{3} \mathrm{~cm}^{-3}$ and no increase in numbers below $30 \mathrm{~nm}$ ), giving confidence that particles measured on the BT Tower were predominantly of local origin and not from regional transport.

\section{Implications and conclusions}

The main pollution source in central London is road traffic, with space heating also a source of emissions. Regional transport is a major source of secondary particulate matter. This work treats the source signature of M. Road as representing the fresh nanoparticle source in London's air. According to the UK Air Quality Expert Group (AGEG, 2005) road traffic accounted for almost $50 \%$ of ultrafine particles $\left(\mathrm{PM}_{0.1}\right)$ emissions in the UK in 2001. Other high temperature sources, notably industries such as electricity generation and iron and steel contribute, but are much less important (AQEG, 2005) and more significantly are with minor exceptions not sited in London. Shi et al. (2001), working in Birmingham (UK) detected nanoparticle plumes from large combustion sources, but concluded that by far the major contributor was road traffic. The other source which needs to be considered is widespread photo-chemically induced nucleation of particles (Kulmala et al., 2007) which occurs quite frequently at rural sites in the UK (Charron et al., 2007). Alam et al. (2003) made detailed measurements in Birmingham (UK), observing that out of a total of 232 days sampling distributed throughout the year, events occurred on only eight days which could be attributed fairly unequivocally to homogeneous nucleation processes, with a further four days possibly attributable. The primary reason is the large condensation sink on existing aerosol available in the UK urban atmosphere, a feature of London to an even greater degree than Birmingham (UK). Consequently, we are confident in attributing the observed sub-50 nm particle fraction predominantly to traffic emissions.

Charron and Harrison (2003) have previously demonstrated that the particle number concentration in roadside air is strongly influenced by the dilution conditions in ways that can be explained by the formation of particles in the mode centred on 20-30 nm by condensation processes in the diluting engine exhaust. This strongly suggests that such particles are semi-volatile and the only previous evidence of their loss by evaporation in the atmosphere (Zhang et al., 2004), 


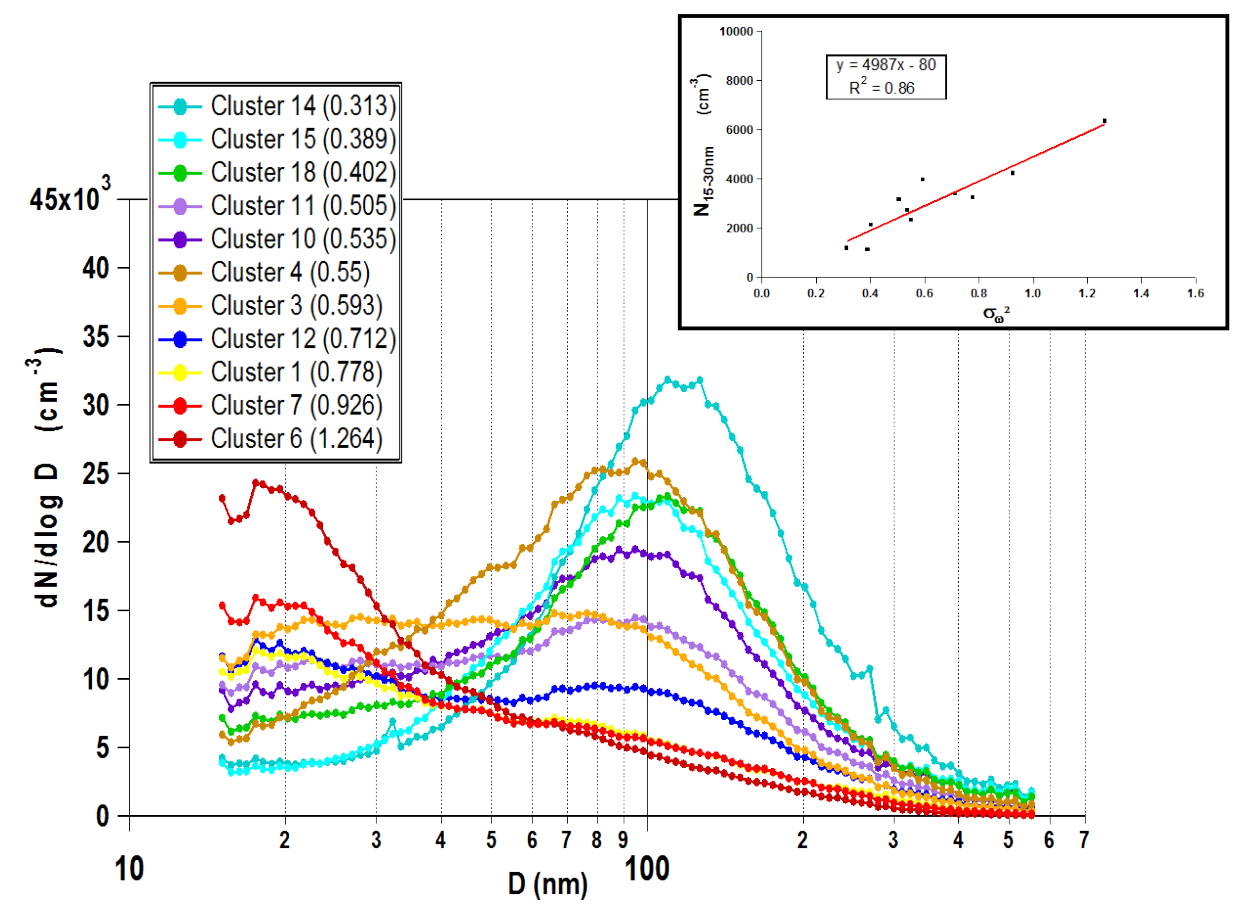

Fig. 8. SMPS clusters analysis found at the BT Tower site. For each of the 11 clusters reported, in the legend an average value of $\sigma_{w}^{2}$ $\left(\mathrm{m}^{2} \mathrm{~s}^{-2}\right)$ BT Tower obtained with the Lidar is given.

as opposed to artificial heating (Kuhn et al., 2005; Biswas et al., 2007) comes from studies downwind of a Californian freeway. Our own group (Shi et al., 1999) and Fushimi and co-workers (Fushimi et al., 2008) have shown a shift in the modal diameter of $>10 \mathrm{~nm}$ particles to larger sizes on moving away from roadside, but both sets of observations could plausibly be explained by dilution of traffic particles to larger sizes by a coarser background aerosol. This study suggests that even within the urban atmosphere, on distance scales of the order of $1 \mathrm{~km}$ and travel times of around $5 \mathrm{~min}$ upon moving away from major emissions sources very significant loss of the nanoparticle fraction is observed which manifests itself in a shift to smaller sizes within R. Park and an almost complete loss of the sub- $30 \mathrm{~nm}$ mode at the BT Tower site such that the size distribution is very similar to that observed at the rural Harwell site in the absence of new particle formation or local emissions (Harrison, 2007; Kuhn et al., 2005). Given that total number concentrations are $\sim 10^{4} \mathrm{~cm}^{-3}$, coagulation will be far too slow to explain significant reduction in particle numbers. As the semi-volatile particles form by condensation onto an involatile core (Ronkko et al., 2007; Sakurai et al., 2003) (typically of sulphuric acid or solid nuclei originating from the engine), it is likely that the cores of particles remain but are too small to be observed with high efficiency with particle counters such as the TSI 3022A. According to Ronkko et al. (2007), the involatile core is about $5 \mathrm{~nm}$ diameter and to Kirchner et al. (2009) 1-3 nm, whilst the efficiency of the $3022 \mathrm{~A}$ is only $50 \%$ at $7 \mathrm{~nm}$, and less be- low this size. Such particles would be subject to very rapid dry deposition processes. The absence of such a mode in the BT Tower data suggests that the involatile core in the London traffic aerosol may be smaller than $5 \mathrm{~nm}$. Gramotnev and Ristovski (2004) also reported a complex evolution of small aerosol traffic modes shifted towards smaller particle size. Our study is much more comprehensive as it considers a number of sites (4) within the London urban area and a very large set of data taken both simultaneously and across different years. Davison et al. (2009) measured inexplicable increasing gradients in particle number concentration with distance from a highway, but the particle numbers were so low that the traffic particles may not have been sampled.

Some of the attempts to model the behaviour of trafficgenerated nanoparticles in the urban atmosphere did not account for their semi-volatility (Gidhagen et al., 2005; Clarke et al., 2004). In comparison, adjustment of the size distribution through coagulation is very slow. Our results demonstrate that any effective model needs to take account of these processes and that particle exposure, both in terms of number concentration and size distribution, are likely to be highly sensitive to the location of sample collection. In a recent paper, Robinson et al. (2007) provide compelling evidence for the partial evaporation of organic particulate emissions with subsequent slow conversion of the volatile fraction to secondary organic aerosol. Our results are highly consistent with the former of these processes. 
The data presented give fascinating insights into the dynamics of particle size distributions in urban air. The times involved in the advection of air polluted by traffic emissions into the centre of R. Park are of the order of $10 \mathrm{~min}$ for wind speeds of $2-5 \mathrm{~m}$ per second and travel distances of $1-2 \mathrm{~km}$ from major source areas. Vertical dispersion of ground-level emissions to the top of the tower takes around $10 \mathrm{~min}$ in conditions of high turbulence, and 20-50 min in more stable conditions (Barlow et al., 2011). Hence on timescales of minutes, substantial evaporative shrinkage (and apparent loss, depending on the measurement device) of traffic-generated nanoparticles is occurring, with potentially far-reaching implications.

In particular, the implications of these results for human health are profound. If the particles which are "lost" have an involatile core, the total number concentration is not immediately changed by the evaporation phenomenon as the particles have simply become too small to be observed by the conventional condensation particle counters. However, the very substantially smaller particles are subject to more rapid loss by coagulation and dry deposition processes. Perhaps more importantly, by virtue of their very high diffusivity, they are unlikely to penetrate the human respiratory system as far as the alveoli, depositing preferentially in the upper airways (ICRP, 1993). In contrast, the peak in the alveolar regional deposition efficiency of particles is around $30 \mathrm{~nm}$, corresponding approximately to the mode in the size distribution in roadside air. However, whatever the true fate of the "lost" particles, it would appear that the threat to human health is reduced by a far greater factor than would be afforded by dispersion and dilution processes alone. This may be a contributory factor in the observations that reductions in $\mathrm{FEV}_{1}$, and $\mathrm{FVC}$ in asthmatic subjects were significantly larger when exposed to ambient air in Oxford Street, London, as opposed to nearby Hyde Park (McCreanor et al., 2007).

Acknowledgements. The authors are grateful to BT for allowing access to the BT Tower and to the Royal Parks for providing facilities at Regent's Park. Funding was provided by the Natural Environment Research Council and BOC Foundation. S. Grimmond (KCL, UK), E. Nemitz (CEH) and W. Bloss provided gas phase pollutant and meteorological data at the BT Tower site and Fay Davies (University of Salford) provided the Doppler Lidar data.

Edited by: E. Nemitz

\section{References}

Alam, A., Shi, J. P. and Harrison, R. M.: Observations of new particle formation in urban air, J. Geophys. Res., 108, 4093-4107, 2003.

AQEG: Particulate Matter in the United Kingdom, Air Quality Expert Group, Department for Environment, Food and Rural Affairs, London, 2005.
Atkinson, R. W., Fuller, G. W., Anderson, H. R., Harrison, R. M., and Armstrong B.: Urban ambient particle metrics and health: A time series analysis, Epidemiology, 21, 501-511, 2010.

Barlow, J. F., Dunbar, T. M., Nemitz, E. G., Wood, C. R., Gallagher, M. W., Davies, F., O'Connor, E., and Harrison, R. M.: Boundary layer dynamics over London, UK, as observed using Doppler lidar during REPARTEE-II, Atmos. Chem. Phys., 11, 2111-2125, doi:10.5194/acp-11-2111-2011, 2011.

Beddows, D. C. S. and Harrison, R. M.: Comparison of average particle number emission factors for heavy and light duty vehicles derived from rolling chassis dynamometer and field studies, Atmos. Environ., 42, 7954-7966, 2008.

Beddows, D. C. S., Dall'Osto, M., and Harrison, R. M.: Cluster analysis of rural, urban and curbside atmospheric particle size data, Environ. Sci. Technol., 43, 4694-4700, 2009.

Bigi, A. and Harrison, R. M.: Analysis of the air pollution climate at a central urban background site, Atmos. Environ., 44, 20042012, 2010.

Birmili, W., Heinke, K., Pitz, M., Matschullat, J., Wiedensohler, A., Cyrys, J., Wichmann, H.-E., and Peters, A.: Particle number size distributions in urban air before and after volatilisation, Atmos. Chem. Phys., 10, 4643-4660, doi:10.5194/acp-10-46432010, 2010.

Biswas, S., Ntziachristos, Moore, K. F., and Sioutas, C.: Particle volatility in the vicinity of a freeway with heavy-duty diesel traffic, Atmos. Environ., 41, 3479-3494, 2007.

Caravaggio, G. A., Charland, J. P., MacDonald, P., and Graham, L.: n-Alkane profiles of engine lubricating oil and particulate matter by molecular sieve extraction, Environ. Sci. Technol., 41, 36973701, 2007.

Charron, A. and Harrison, R. M.: Primary particle formation from vehicle emissions during exhaust dilution in the roadside atmosphere, Atmos. Environ., 37, 4109-4119, 2003.

Charron, A. and Harrison, R. M.: Comparison between SMPS, Nano-SMPS and ephiphaniometer data at an urban background site (Bloomsbury) and a roadside site (Marylebone Road), Report to DEFRA by University of Birmingham and Cassella Stanger under contract EPG 1/3/184, 2005.

Charron, A., Birmili, W., and Harrison, R. M.: Factors influencing new particle formation at the rural site, Harwell, United Kingdom, J. Geophys. Res., 112, D14210, doi:10.1029/2007JD008425, 2007.

Clarke, A. G., Robertson, L. A., Hamilton, R. S., and Gorbunov, B.: A Langrangian model of the evolution of the particulate size distribution of vehicular emissions, Sci. Total Environ., 334-335, 197-206, 2004.

Dall'Osto, M., Harrison, R. M., Coe, H., and Williams, P.: Realtime secondary aerosol formation during a fog event in London, Atmos. Chem. Phys., 9, 2459-2469, doi:10.5194/acp-9-24592009, 2009a.

Dall'Osto, M., Harrison, R. M., Coe, H., Williams, P. I., and Allan, J. D.: Real time chemical characterization of local and regional nitrate aerosols, Atmos. Chem. Phys., 9, 3709-3720, doi:10.5194/acp-9-3709-2009, 2009 b.

Davidson,C., Phalen, R., and Solomon, P.: Airborne particulate matter and human health: a review, Aerosol Sci. Technol., 39, 737-749, 2005.

Davison, B., Duncan, W., and Boardman, C.: Aerosol Evolution from a Busy Road in North West England., Meteorol. Z., 18, 55- 
60, 2009.

Despiau, S. and Croci, D.: Concentrations and size distributions of fine aerosol particles measured at roof level in urban zone, J. Geophys. Res.-Atmos., 112(D9), D09212, doi:10.1029/2006JD007228, 2007.

Dunlea, E. J., Herndon, S. C., Nelson, D. D., Volkamer, R. M., San Martini, F., Sheehy, P. M., Zahniser, M. S., Shorter, J. H., Wormhoudt, J. C., Lamb, B. K., Allwine, E. J., Gaffney, J. S., Marley, N. A., Grutter, M., Marquez, C., Blanco, S., Cardenas, B., Retama, A., Ramos Villegas, C. R., Kolb, C. E., Molina, L. T., and Molina, M. J.: Evaluation of nitrogen dioxide chemiluminescence monitors in a polluted urban environment, Atmos. Chem. Phys., 7, 2691-2704, doi:10.5194/acp-7-2691-2007, 2007.

Fushimi, A., Hasegawa, S., Takahashi, K., Fujitani, Y., Tanabe, K., and Kobayashi, S.: Atmospheric fate of nuclei-mode particles estimated from the number concentrations and chemical composition of particles measured at roadside and background sites, Atmos. Environ., 42, 949-959, 2008.

Gramotnev, G. and Ristovski, Z.: Experimental investigation of ultra-fine particle size distribution near a busy road, Atmos. Environ., 38, 1767-1776, 2004.

Gidhagen, L., Johansson, C., Langner, J., and Foltescu, V. L.: Urban scale modeling of particle number concentration in Stockholm, Atmos. Environ., 39, 1711-1725, 2005.

Harrison, R. M. and Yin, J.: Carbonaceous aerosol in central England: Sources and Processes, Atmos. Environ. 42, 1413-1423, 2008.

Harrison, R. M., Shi, J. P., Xi, S., Khan, A., Mark, D., Kinnersley, R., and Yin, J.: Measurement of number, mass and size distribution of particles in the atmosphere, Philos. T. Roy. Soc. Lond., A, 358, 2567-2580, 2000.

Harrison, R. M.: Nanoparticles in the Atmosphere, Issues in Environmental Science and Technology, No. 24, Nanotechnology: Consequences for Human Health and the Environment, Royal Society of Chemistry, Cambridge, 35-49, 2007.

Harrison, R. M., Beddows, D. C. S., and Dall'Osto, M.: PMF analysis of wide-range particle size spectra collected on a major highway, Environ. Sci. Technol., 45, 5522-5528, 2011 a.

Harrison, R. M., Dall'Osto, M., Beddows, D. C. S., Thorpe, A. J., Allan, J., Coe, H., Dorsey, J., Gallagher, M., Martin, C., Whitehead, J., Williams, P., Benton, A. K., Jones, R. L., Langridge, J., Ball, S., Langford, B., Hewitt, C. N., Davison, B., Martin, D., Petersson, K., Henshaw, S. J., White, I. R., Shallcross, D. E., Barlow, J. F., Dunbar, T., Davies, F., Nemitz, E. G., Phillips, G., and Helfter, C.: Atmospheric chemistry and physics in the atmosphere of a developed megacity (London): An overview of the REPARTEE experiment and its conclusions, Atmos. Chem. Phys. Discuss., in preparation, $2011 \mathrm{~b}$.

ICRP: Human Respiratory Tract Model for Radiological Protection, International Commission on Radiological Protection, Publication 66, Pergamon, 1993.

Jacobson, M. Z., Kittelson, D. B., and Watts, W. F.: Enhanced coagulation due to evaporation and its effect on nanoparticle evolution, Environ. Sci. Technol., 39, 9486-9492, 2005.

Janhäll, S., Olofson, K. F. G., Andersson, P., Pettersson, J .B. C., and Hallquist, M.: Evolution of the urban aerosol during winter temperature inversion episodes, Atmos. Environ., 40, 53555366, 2006.

Kerminen, V. M., Pakkanen, T. A., Makela, T., Hillamo, R. E., Sil- lanpaa, M., Ronkko, T., Virtanen, A., Keskinen, J., Pirjola, L., Hussein, T., and Hameri, K.: Development of particle number size distribution near a major road in Helsinki during an episodic inversion situation, Atmos. Environ.,41, 1759-1767, 2007.

Kirchner, U., Scheer, V., Vogt, R., and Kägi, R.: TEM study on volatility and potential presence of solid cores in nucleation mode particles from diesel powered passenger cars, Aerosol Sci., 40, 55-64, 2009.

Kuhn, T., Biswas, S., and Sioutas, C.: Diurnal and seasonal characteristics of particle volatility and chemical composition in the vicinity of a light-duty vehicle freeway, Atmos. Environ., 39, 7154-7166, 2005.

Kulmala, M., Riipinen, I., Sipilä, M., Manninen, H. E., Petäjä, T., Junninen, H., Dal Maso, M., Mordas, G., Mirme, A., Vana, M., Hirsikko, A., Laakso, L., Harrison, R. M., Hanson, I., Leung, C., Lehtinen, K. E. J., and Kerminen V.-M.: Towards direct measurement of atmospheric nucleation, Science, 318, 89-92, 2007.

Kumar, P., Fennell, P. S., Hayhurst, A. N., and Britter, R. E.: Street versus rooftop level concentrations of fine particles in a cambridge street canyon, Bound.-Lay. Meteorol., 131, 3-18, 2009.

Li, X. L., Wang, J. S., Tu, X. D., Liu, W., and Huang, Z.: Vertical variations of particle number concentration and size distribution in a street canyon in Shanghai, China, Sci. Total Environ., 378, 306-316, 2007.

Lipsky, E. M. and Robinson, A. L.: Effects of dilution on fine particle mass and partitioning of semivolatile organics in diesel exhaust and wood smoke, Environ. Sci. Technol., 40, 155-162, 2006.

Martin, C. L., Longley, I. D., Dorsey, J. R., Thomas, R. M., Gallagher, M. W., and Nemitz, E.: Ultrafine particle fluxes above four major European cities, Atmos. Environ., 43, 4714-4721, 2009.

McCreanor, J., Cullinan, P., Nieuwenhuijsen, M. J., Stewart-Evans, J., Malliarou, E., Jarup, L., Harrington, R., Svartengren, M., Han, I.- K., Ohman-Strickland, P. O., Chung, K. F., and Zhang, J.: Respiratory effects of exposure to diesel traffic in persons with asthma, N. Eng. J. of Med., 357, 2348-2397, 2007.

Morawska, L., Ristovski, Z., Jayaratne, E. R., Keogh, D. U., and Ling X.: Ambient nano and ultrafine particles from motor vehicle emissions: Characteristics, ambient processing and implications on human exposure, Atmos. Environ., 42, 8113-8138, 2008.

Nemitz, E., Phillips, G. J., Di Marco, C. F., Allan, J., Barlow, J. F., Coe, H., Thorpe, A., Dall'Osto, M., Harrison, R. M., and Williams, P. I.: Controls of concentrations, gradients and fluxes of inorganic reactive gases and aerosol components above London, in preparation, 2011.

Ntziachristos, L., Ning, Z., Geller, M. D., and Sioutas, C.: Particle concentration and characteristics near a major freeway with heavy-duty diesel traffic, Environ. Sci. Technol., 41, 2223-2230, 2007.

Pearson, G. N., Davies, F., and Collier, C. G.: An analysis of the performance of the UFAM pulsed Doppler Lidar for observing the boundary layer, J. Atmos. Oceanic Tech., 26, 240-250, 2009.

Robinson, A. L., Donahue, N. M., Shrivastava, M. K., Weitkamp, E. A., Sage, A. M., Grieshop, A. P., Lane, T. E., Pierce, J. R., and Pandis, S. N.: Rethinking organic aerosols: Semivolatile emissions and photochemical aging, Science, 315, 1259-1262, 2007.

Ronkko, T., Virtanen, A., Kannosto, J., Keskinen, J., Lappi, M., and Pirjola, L.: Nucleation mode particles with a nonvolatile core in 
the exhaust of a heavy duty diesel vehicle, Environ. Sci. Technol., 41, 6384-6389, 2007.

Sakurai, H., Tobias, H. J., Park, K., Zarling, D., Docherty, K. S., Kittelson, D. B., McMurry, P. H., and Ziemann, P. J.: On-line measurements of diesel nanoparticle composition and volatility, Atmos. Environ., 37, 1199-1210, 2003.

Schelle-Kreis, J., Sklorz, M., Orasche, J., Stolzel, M., Peters, A., and Zimmermann, R.: Semi volatile organic compounds in ambient $\mathrm{PM}_{2.5}$. Seasonal trends and daily resolved source contributions, Environ. Sci. Technol., 41, 3821-3828, 2007.

Seaton, A., Godden, D., MacNee, W., and Donaldson, K.: Particulate air pollution and acute health effects, Lancet, 345, 176-178, 1995.

Shi, J. P. and Harrison, R. M.: Investigation of ultrafine particle formation during diesel exhaust dilution, Environ. Sci. Technol., 33, 3730-3736, 1999.

Shi, J. P., Khan, A. A., and Harrison, R. M.: Measurements of ultrafine particle concentration and size distribution in the urban atmosphere, Sci. Total Environ., 235, 51-64, 1999.

Shi, J. P., Mark, D., and Harrison, R. M.: Characterization of particles from a current technology heavy-duty diesel engine, Environ. Sci., Technol., 34, 748-755, 2000.

Shi, J. P. Evans, D. E., Khan, A. A., and Harrison, R. M.: Sources and concentrations of nanoparticles $(<10 \mathrm{~nm}$ diameter $)$ in the urban atmosphere, Atmos. Environ. 35, 1193-1202, 2001.

Siebert, P., Beyrich, F., Gryning, S.-E., Joffre, S., Rasmussen, A., and Tercier, P.: Review and intercomparison of operational methods for the determination of the mixing height, Atmos. Environ., 34, 1001-1027, 2000.
Thorpe, A. and Harrison, R. M.: Sources and properties of nonexhaust particles from road traffic: a review, Sci. Total Environ., 400, 270-282, 2008.

Wehner, B., Siebert, H., Ansmann, A., Ditas, F., Seifert, P., Stratmann, F., Wiedensohler, A., Apituley, A., Shaw, R. A., Manninen, H. E., and Kulmala, M.: Observations of turbulence-induced new particle formation in the residual layer, Atmos. Chem. Phys., 10, 4319-4330, doi:10.5194/acp-10-4319-2010, 2010.

Williams, P. I., McFiggans, G., and Gallagher, M. W.: Latitudinal aerosol size distribution variation in the Eastern Atlantic Ocean measured aboard the FS-Polarstern, Atmos. Chem. Phys., 7, 2563-2573, doi:10.5194/acp-7-2563-2007, 2007.

Zhu, Y. F., Hinds, W. C., Kim, S., Shen, S., and Sioutas, C.: Study of ultrafine particles near a major highway with heavy-duty diesel traffic, Atmos. Environ., 36, 4323-4335, 2002.

Zhang, K. M. and Wexler, A. S.: Evolution of particle number distribution near roadways Part I: analysis of aerosol dynamics and its implications for engine emission measurement, Atmos. Environ., 38, 6643-6653, 2004.

Zhang, K. M., Wexler, A. S., Zhu, Y. F., Hinds, W. C., and Sioutas, C.: Evolution of particle number distribution near roadways. Part II. The road-to-ambient processes, Atmos. Environ., 38, 66555556, 2004. 